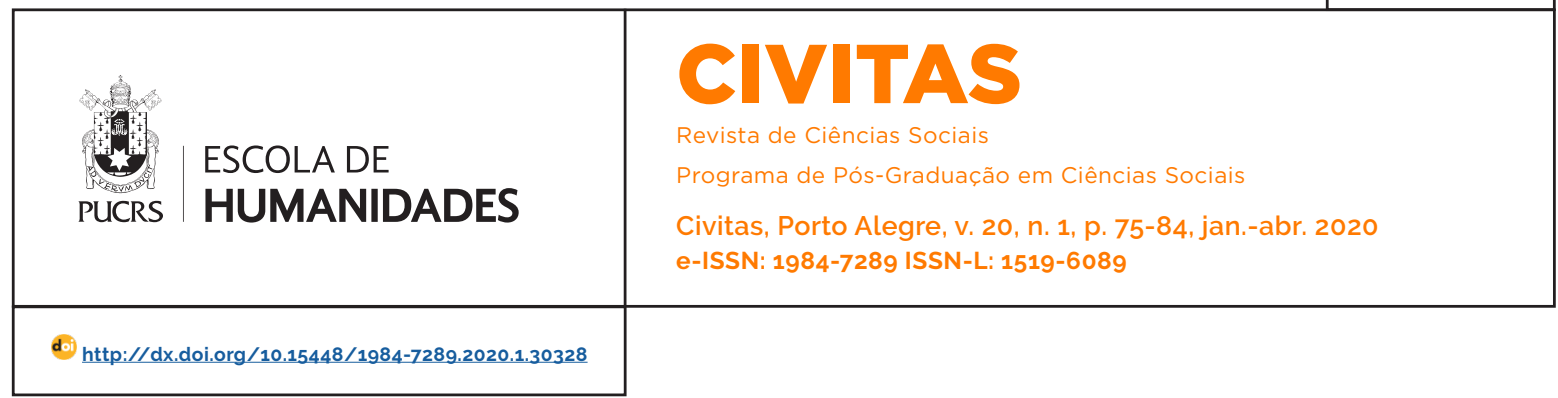

ARTIGOS / ARTICLES

\title{
Cuestionando la blanquedad de la nación: configuraciones identitarias afrodescendientes y "cultura afro" en Buenos Aires (Argentina)
}

\author{
Questionando a branquitude da nação: configurações de identidades africanas e \\ "cultura afro" em Buenos Aires (Argentina) \\ Questioning the whiteness of the nation: afrodescendant identity configurations and \\ "Afro culture" in Buenos Aires (Argentina)
}

\section{Eva Lamborghini ${ }^{1}$ \\ orcid.org/0000-0001-6721-8408 \\ lamborghinieva@yahoo.com.ar}

Maria Cecilia Martino ${ }^{1}$

orcid.org/0000-0002-9904-2010 maricelmartino@gmail.com

Recebido em: 10 abr. 2018 Aprovado em: 29 ago. 2019 Publicado em: 25 mai. 2020

\section{(c) (1)}

Artigo está licenciado sob forma de uma licença Creative Commons Atribuição 4.0 Internacional.
Resumen: En las últimas décadas, la sociedad argentina experimenta un progresivo cuestionamiento de su pretendida "blanquedad". Desde mediados de la década de 1990, se gestó un movimiento social afrodescendiente conformado por organizaciones que luchan por su revisibilización, contra el racismo y la exclusión. Asimismo, la llegada de migrantes afrodescendientes dedicados a enseñar artes afrolatinoamericanas, fue articulándose con este movimiento político y creciendo como campo cultural a medida que aprendices y practicantes argentinos devinieron, también, docentes y referentes. Fruto de nuestros respectivos trabajos etnográficos en la ciudad de Buenos Aires, en este artículo problematizaremos algunas de las des/articulaciones que se suscitan entre la configuración de identidades y memorias afrodescendientes y la práctica y resignificaciones de expresiones culturales afro. Analizaremos estas vinculaciones, en primer lugar, en el caso de jóvenes que se autoidentifican afrodescendientes en un marco mayor de visibilización y reivindicación de la temática y, en segundo lugar, en actores sociales que practican cultura afro más allá de estas pertenencias étnico-raciales. Aspiramos a contribuir a la comprensión de las complejas relaciones entre racializaciones, etnicizaciones, expresividad cultural y política en el contexto local. Palabras clave: Identificaciones afrodescendientes. Cultura afro. Resignificaciones. Buenos Aires/Argentina.

Resumo: Nas últimas décadas, a sociedade argentina experimentou um questionamento progressivo de sua suposta "branquitude". Desde meados da década de 1990 foi criado um movimento social afrodescendente, formado por organizações que lutam por sua revisibilização, contra o racismo e a exclusão. Além disso, a chegada de migrantes afro-descendentes, dedicados ao ensino das artes afro-latino-americanas, articulou-se com esse movimento político e cresceu como campo cultural, à medida que os aprendizes e praticantes argentinos tornaram-se, também, professores e referentes. Fruto de nossos respectivos trabalhos etnográficos, neste artigo tentaremos problematizar algumas das articulações que surgem entre as configurações de identidades e memórias afrodescendentes, a própria prática e as ressignificações das expressões afro-culturais. Analisaremos esses vinculos, em primeiro lugar, no caso de jovens que se identificam como afrodescendentes em um contexto mais amplo de visibilidade e reivindicações sociais em relação ao tema, e, em segundo lugar, entre atores sociais que praticam a cultura afro além de seus pertencimentos étnico-raciais. Desta forma procuramos contribuir para a compreensão das complexas relações entre racializações, etnicizações, a expressividade cultural e política no contexto local.

Palavras-chave: Identificações afro-descendentes. Culturas negras/afro. Ressignificações. Buenos Aires/Argentina.

Abstract: In recent decades, Argentine society has experienced a progressive questioning of its alleged "whiteness". Since the mid-1990s, an Afro-descendant 
Social Movement has been created by organizations that are fighting for their revitalization, against racism and exclusion. In addition, the arrival of Afro-descendant migrants dedicated to teach Afro-Latin American arts, was articulates with this political movement and grew as a cultural field, as Argentine apprentices and practitioners become, also, teachers and referents. As a result of our respective ethnographic field work, in this article we will problematize some of the de / articulations that grows between the configuration of afrodescendant identities and memories, and the practice and the resignifications of Afro cultural expressions. We will analyze these connections, first, in the case of young people who identify themselves as Afro-descendants in a broad context of visibility and social vindications of their identities and, secondly, between social actors who practice Afro culture beyond these ethno-racial belongins. We aspire to contribute to the understanding of these complex relations between racialization, ethnicization, cultural and political expressivity in the local context.

Keywords: Afro-descendant identifications. Afro/black cultures/arts. Resignifications. Buenos Aires Argentina

\section{Introducción: La blanquedad argentina en cuestión ${ }^{2}$}

En Argentina, la supuesta "desaparición" de la población afroargentina se admitió como certeza una y otra vez desde las últimas décadas del siglo XIX (Geler 2010). En el contexto de consolidación del aparato estatal moderno, fue cimentándose una narrativa dominante de la nación pretendidamente blanca y europea (Frigerio 2006) y su correspondiente narrativa sobre una "cultura nacional" eurodescendiente (Dominguez 2004; Corti 2015). Así, la identidad argentina, y la porteña como su expresión más acabada, se configuraron bajo el ideal de blanquedad homogénea - y no de mestizaje como en otras naciones latinoamericanas (Frigerio 2006). Históricamente, se excluyó la "negritud racial" de lo nacional, se estigmatizó la "negritud popular" (Geler 2016)³ y se regularon y reprimieron las expresiones culturales "negras" en el espacio público (Geler 2011; Lamborghini 2015).

Sin embargo, en las últimas décadas, se destaca la formación de un movimiento social de afrodescendientes que luchan por su revisibilización y por el reconocimiento de sus aportes sociales y culturales a la nación, contra el racismo, la exclusión y por la igualdad (Frigerio y Lamborghini 2011a, 2011b). Asimismo, las trayectorias de migrantes afrodescendientes de distintas nacionalidades y su papel en la conformación de un "circuito cultural afro" (Domínguez 2004) dieron lugar a una escena de práctica y enseñanza de manifestaciones culturales afrolatinoamericanas que tuvo un papel destacado en la re-visibilización de la cuestión afro (Frigerio y Lamborghini 2011a, 2011b). Este campo de actividades artísticas se fue vinculando con el movimiento político afrodescendiente en un marco de valorización multicultural de expresiones marcadas étnicamente y ampliándose a distintos sectores sociales (Lamborghini 2015).

Teniendo en cuenta estos dos desarrollos y sus conexiones -movimiento político afrodescendiente y circuito cultural afro- en este artículo nos proponemos poner en diálogo dos dimensiones del dinámico y heterogéneo campo de estudios sobre afrodescendencia en Argentina (Lamborghini, Geler y Guzmán 2017). Fruto de nuestros trabajos de investigación etnográfica, problematizaremos algunas de las des/articulaciones que se suscitan entre la configuración de identidades y memorias afrodescendientes y la práctica y resignificación de expresiones culturales afrolatinoamericanas a partir de dos esferas discursivas y de acción delimitadas analíticamente. En primer lugar, reconstruiremos el caso de los y las jóvenes que devienen de familias argentino-caboverdianas planteando cómo algunos de ellos/ellas se valen de ciertos recursos culturales (prácticas, saberes, historias) que entran en tensión con la propia historia y trayectoria familiar de los argentino-caboverdianos en el país. ${ }^{4}$ En segundo lugar, nos basaremos en aspectos relacionados con procesos de resignificación de

\footnotetext{
2 Este artículo ha sido realizado en el marco del PICT 2014-1289-FONCYT-MINCYT y del P. BID PICT 2014 n. 1211.

Con fines analíticos, Geler (2016) denomina a la diferenciación entre negros y "negros" (Frigerio 2006) como negritud racial y negritud popular, categorias que subrayan cómo en la Argentina contemporánea, la clase social no prescinde de una dimensión racial, ni la racial de una dimensión de clase.

4 Este planteo está basado en el trabajo de campo realizado en el marco de una investigación doctoral llevada a cabo entre inmigrantes caboverdianos y argentinos de distintas generaciones ligados a las instituciones caboverdianas de Buenos Aires. En ella se buscó reconstruir un proceso de re-definiciones de identidades y categorias que gravitaron en torno a la identidad africana/caboverdiana/ argentina, tanto desde un encuadre nacional como transnacional, a partir de conceptos ligados a las trayectorias, las memorias e identidades juveniles, generacionales y étnico-raciales (Martino 2015, 2016, 2017).
} 
expresiones culturales afrolatinoamericanas en sectores sociales de la ciudad de Buenos Aires que trascienden pertenencias o adscripciones étnico-raciales afrodescendientes. ${ }^{5}$

Veremos que, así como la práctica de una "cultura popular negra" (Hall 2003) puede tener como aprendizaje el ámbito de un taller de enseñanza (en contraste con un proceso vía socialización familiar) en los dos casos, las relaciones de identificación con la dimensión "negra/afro" de esta práctica cultural se producen a partir de énfasis y preocupaciones distintas. De manera general, intentaremos contribuir a las reflexiones en torno a la pluralidad de actores y a la diversidad de formas, convergentes, divergentes y cambiantes de disputar la narrativa hegemónica de la "Argentina blanca".

\section{Identificaciones y memorias afro/negras/} caboverdianas en tensión, el caso de los y las jóvenes argentino-caboverdianos/as

En relación con las identidades gestadas en contextos de movilización política -como los que hemos venido analizando entre los afrodescendientes- $-{ }^{6}$ seguimos la propuesta de una serie de autores que proponen entender las identificaciones como actos situados en contextos e interacciones especificos. Hall (2010) retoma con fuerza los anclajes relacionales de las identidades y su ubicación histórica de acuerdo a coordenadas espacio-temporales, que involucran tanto al pasado como al presente. En esta línea, subraya que toda identidad es un posicionamiento (un acto de identificación, cuyo papel se efectúa por dentro de la representación) y que este contempla la construcción de una relación con el pasado que es problemática y pasará a enmarcar este posicionamiento particularizado. En general, la reconstrucción del pasado que realizan los y las jóvenes que devienen de familias argentino-caboverdianas puede comprenderse en términos de un "acto de reunificación imaginaria" (Otero Correa 2000) de una historia que no ha sido vivida, y con la cual, sin embargo, se entabla un diálogo en la distancia. Este diálogo encuadra y redefine las fronteras de lo étnicamente diferente, y en algunos casos va más allá de éstas, para incorporar nuevas experiencias a esta representación identitaria, con sus propias tensiones y dilemas. En este sentido, a diferencia de las generaciones llegadas como inmigrantes, los y las jóvenes entablan una búsqueda situada en el presente, a partir del cual indagan el pasado y se diferencian en términos generacionales. ${ }^{7}$ En el testimonio plasmado a continuación, podemos observar el lugar que puede ocupar la práctica de una determinada arte negra en estas configuraciones identitarias:

Yo tengo cinco años de capoeira y cuando empecé a hacer más o menos a los diecisiete, buscando otras cosas e indagando dentro de la capoeira a los viejos caboverdianos Ise refiere a caboverdianos que solian ir a la institución de Dock Sud]. Qué conocian de la capoeira, porque ellos tienen una forma de pelear a las patadas, por lo que yo escucho, que es muy similar a lo que es la capoeira, y hay otras teorias que dicen que el berimbau es de Cabo Verde entonces, como que la capoeira, y Cabo Verde están unidos [...] además es posible porque las islas eran un lugar de paso, de barcos. Y a partir de ese momento uno empieza a decirse, bueno, yo soy afro, sé que soy hija de caboverdianos pero ¿cómo es? ¿De dónde son? ¿Dónde estaban? ¿Por qué fueron ahi ¿por qué vinieron acá?... y te empezás a preguntar un montón de cosas, ¿en qué situación?...si en situación de esclavos... es la búsqueda interna de saber quién es una y de encontrar un lugar (Lucia, entrevista biográfica, 10/08/2009, Ciudad de Buenos Aires). ${ }^{8}$

\footnotetext{
5 Este desarrollo tiene como base el trabajo de campo realizado en el marco de una investigación doctoral y postdoctoral con foco en la práctica y resignificaciones del candombe afrouruguayo en la ciudad de Buenos Aires, en relación con procesos y cambios de la escena cultural y política contemporánea mayor. A través de la puesta en diálogo de distintos marcos analiticos referidos a "estudios afro-latinoamericanos", "culturas juveniles" y "nuevos movimientos sociales", se destaca la multidimensionalidad y interseccionalidad necesaria para su abordaje (Lamborghini 2015, 2017a).

6 A partir de las reuniones de Santiago de Chile (2000) y Durban (2001), a las que concurrió una delegación afroargentina, gran parte de los activistas afroargentinos retomará el término "Afrodescendiente" como categoría de autoadscripción, surgida del propio movimiento afro, (Lao Montes 2009) y (Maffia 2011).

7 Tomaremos una definición amplia de lo generacional como categoria temporal multidimensional, organizada en función de experiencias históricas, simbólicas y culturales que generan procesos de subjetivación expresados en clave de edad, que fortalecen y delimitan vinculos sociales (Margulis y Urresti 2008 entre otros).

8 Lucia es argentina, al momento de la entrevista tenía 23 años y es descendiente de caboverdianos por el lado paterno. Utilizamos seudónimos para preservar el anonimato de las personas entrevistadas y/o mencionadas
} 
Lucía relata un momento de indagación vivido a partir de su práctica como capoeirista, y marca una diferenciación entre saber que es hija de caboverdianos y ser afro, que expresa cómo lo afro se constituye como un posicionamiento -a partir de la vinculación que Lucía efectúa entre practicar capoeira, investigar sobre esta práctica e indagar sobre la presencia de la capoeira entre los viejos-, entre otras cuestiones. Como señala Dominguez (2004), lo afro se constituye en una categoría abarcativa que condensa elementos simbólicos referidos a las vivencias asociadas a los "negros" en el país como la memoria de un pasado esclavo, la asunción de una particularidad cultural que representa la presencia africana en América y el reconocimiento de una posición histórica subalternizada. Como podemos ver en este relato, en esta búsqueda, la historia de Cabo Verde queda ligada a la historia la esclavitud, que es usualmente desenfatizada en otros contextos. Por otro lado, ella sabe que es hija de caboverdianos, posiblemente a partir de las diferentes experiencias de marcación cotidiana transitadas fundamentalmente en el jardín-escuela, como veremos enseguida. En algunos casos, estos procesos le permiten forjar una vinculación con la historia familiar que se tensiona con su propio recorrido. En una conversación mencionó:

[...] mi mamá fue de incentivarnos a nosotros [...] ella siempre me cuenta algo del jardin, que mi maestra me preguntaba a mi ¿y tu mamá cómo es? [Imita la respuesta suya en la niñez] 'mi mamá es blanca' ¿y tu papá cómo es? Y yo respondia, 'mi papá es negro, negro del África' le decia yo. Y mi mamá estuvo siempre ahi la continuación intenta reproducir la voz de su madre] 'porque ustedes son caboverdianos' [...], siempre estuvo ahi apoyando mucho más que mi padre que estuvo muy alejado de la Sociedad [refiere a la institución caboverdiana], la generación de mi papá se alejó completamente (Lucia. entrevista biográfica, 05/02/2009, Ciudad de Buenos Aires).
Cuando la segunda autora se reunió por primera vez con Lucía en un bar -que en ese entonces participaba de varias actividades en la Sociedad Caboverdeana que estaba documentando-, Lucía le aclaró que hacía dos tipos de actividades, unas "son propias de la colectividad" y otra "son específicamente afros". Esta distinción resultó llamativa dado que al momento de la investigación parecian formar parte de un único conjunto. En ese entonces, las actividades de la institución estaban volcadas a visibilizar la presencia negra en el país, a partir de la organización de festivales con amplia participación de cara al Censo Nacional de Población (2010).9 A medida que la investigación avanzó resultó claro que no todas las actividades estaban necesariamente vinculadas, y que ello hablaba sobre los papeles que juegan lo negro/ lo afro y lo caboverdiano en esta historia. Lo significativo es que, en ocasiones, el apelativo afro/afrodescendiente/negro toma distancia de la historia caboverdiana, aunque esta parte de la historia constituya una suerte de "marco" desde el cual algunos jóvenes emprenden esta búsqueda. La diferenciación entre "ser caboverdiano" /"ser negro"/"ser afro" aunque lógicamente resignificada, está ligada a una compleja historia colonial en la cual Cabo Verde en general, y los caboverdianos en particular recibieron un tratamiento diferenciado por parte de Portugal, marcando una jerarquía en relación a otras colonias continentales. Esta narrativa, fue recontextualizada en Argentina entre las diferentes generaciones de inmigrantes que formaron parte de las asociaciones caboverdianas de Dock Sud y Ensenada (Maffia 2010, 2011; Martino 2015). ${ }^{10}$ Importante es aclarar que esto se combinó con el propio proceso de desadscripción transitado por los hijos de las familias argentinocaboverdianas, que abandonaron prácticas que

\footnotetext{
9 Los festivales realizados en el año 2009: "Argentina Negra I", "Argentina Negra II" y un tercero, "Argentina Negra III, ies mujer!" realizado en el 2010, fueron coordinados por la Sociedad caboverdiana de Dock Sud. En ellos se organizaron actividades de difusión y promoción de aspectos culturales de la población de origen africano local, mediante números artísticos, performances, y en menor medida mesas debate en las cuales participaron jóvenes ligados a la Sociedad caboverdiana de Dock Sud, con gran convocatoria.

10 Varios de estos grupos, integrados en la dirigencia institucional de las asociaciones, buscaron desenfatizar por varios medios cualquier vínculo con lo africano. Con significativos periodos de quiebre y redefiniciones encabezados fundamentalmente por los jóvenes, lo que activó conflictos de diferente intensidad entre generaciones (décadas de 1940-50 y décadas de 1970 y 1980), esta narrativa logró persistir, para comenzar a redefinirse, lentamente, desde finales de 1990 (Martino 2015, 2017).
} 
los identificaban espontáneamente como "hijos de caboverdianos": empleos en la navegación, vínculos con la institución social, escolarización, vivienda en un barrio característico, parejas con caboverdianas/os, entre otros. Del análisis de las entrevistas y fragmentos biográficos se sugirió que las denominadas segundas generaciones se enfrentaron de forma más patente a marcaciones y estigmatizaciones que en algunos casos devenian en situaciones de discriminación racial, y se hacian presentes en diferentes contextos: fundamentalmente en la escuela, aunque también en los bares, discotecas, entre otros espacios que fueron enunciados en diversas entrevistas (Martino 2015).

En estas situaciones relatadas, emergía una fuerte adscripción por otros configurada a partir de la mirada ${ }^{11}$ que hacia énfasis en las diferencias fenotípicas, e interactuaba de forma compleja con el proceso de desadscripción efectuado por los descendientes de inmigrantes en general y por los caboverdianos en particular (Martino 2015). Se configuraba una negritud percibida como una presencia extraña, dislocada y "fuera de contexto", puesto que no había etnicidad en la cual enmarcarla, y por ello resultaba más estigmatizante que otros tipos de racialización (Briones 2002). Teniendo en cuenta estos procesos, se podria proponer entonces que los más jóvenes comenzaron a descubrirse negros/afro cuando se desmarcaron como caboverdianos. Paradójicamente, en esas experiencias pasaron a saber que eran hijos/as/ nietos/as/bisnietos/as de caboverdianos. Será en el contexto de las denominadas "políticas de la identidad" cuando estos jóvenes retornen a esta historia familiar con nuevas preguntas. Y será en este proceso de descubrimiento, que algunas artes negras, permitirán redefinir esta historia, introduciendo sentidos que se tensionan con aquellos presentes en las memorias e historias familiares, y permitiéndoles desarrollar formas más abarcativas y heterogéneas de vincularse con lo afro (Martino 2016). En resumen, estas apropiaciones particularizadas introducen una cantidad de saberes aprendidos de otros contextos - como la capoeira, pero también percusión. candombe, danzas afro, rap, fotografía y filmación - que en algunos casos involucran una apropiación que va más allá - dado que complejiza - la asociación por membrecía familiar caboverdiana.

\section{Cultura afro más allá de identificaciones afrodescendientes}

A diferencia de la clásica búsqueda de "africanismos" o sincretismos en América, los trabajos actuales apelan a la historicidad y a la no esencialización de las prácticas culturales analizadas en contexto. En sintonía con estos cambios, nociones como "cultura negra" (Frigerio 2000), "cultura popular negra" (Hall 2003), o incluso más constructivistas como "culturas negras" (Sansone 2003), han ido dejando paso al uso de categorias menos marcadas racialmente. Se habla entonces de expresiones, manifestaciones, prácticas culturales, artes o artes performáticas: "afro-latinoamericanas" (o su inscripción nacional); "afrodescendientes"; "de raíz negra"; "de raíz africana", "de matriz africana"; "de origen afro", "de origen africano", etc. en contextos nacionales o en su circulación a través de las fronteras. De estos términos, que no son necesariamente equivalentes, la categoría "afro" se plantea como la más abarcadora, "engloba una gran diversidad de expresiones que requieren ser ubicadas histórica y culturalmente" (Juárez Huet y Rinaudo 2017). ${ }^{12}$

En Buenos Aires, la escena de cultura afro está mayormente delineada entre múltiples talleres de enseñanza y su práctica, ya sea en el espacio público, ya sea en otro tipo de eventos como recitales, ciclos culturales, fiestas, etc. Este circuito autónomo de expresiones culturales afrolatinoamericanas - candombe afrouruguayo, danzas de orixás y capoeira afrobrasileñas, músicas y danzas afroperuanas, entre otras -, fue creciendo

\footnotetext{
11 En las entrevistas realizadas aparece constantemente el tema de la mirada, una mirada configurada a partir de una "ceguera cromática" naturalizada (Frigerio 2006) que focaliza cualquier presencia negra dentro del paradigma de la "negritud racial" (Geler 2016) visualmente conceptualizada como extranjera (Frigerio 2006: Geler 2016).

12 En el contexto de Buenos Aires, estas formas de denominación circulan en el dinámico "campo afro", que incluye a investigadores de la temática, entre sus múltiples actores (Fernández Bravo 2012).
} 
y vigorizándose en la medida en que aprendices y practicantes argentinos fueron incorporando estos saberes y sumándose también como referentes en procesos de difusión. De este modo, el circuito cultural afro local no sólo involucra contextos de transmisión guiados por trabajadores y/ o activistas culturales afrodescendientes, sino también una cantidad de docentes y sobre todo practicantes que muchas veces transitan fluidamente entre varias expresiones culturales, se identifican con "culturas negras" y las relocalizan mediante marcas y sellos propios, más allá de pertenencias e identificaciones étnico-raciales "afro" (Lamborghini 2017a, 2017b). En este caso, la dimensión de la negritud puede aparecer también como un tópico a des-velar y es frecuente que el aprendizaje de alguna manifestación cultural afro lleve a quien la incorpora a preguntarse por el rol de los africanos esclavizados y sus descendientes en la historia nacional, encontrando y reivindicando una "raíz negra" en la sociedad y cultura argentina que pone en cuestión su supuesta blanquedad (Domínguez 2004; Lamborghini 2015, 2017b; Corti 2015).

En la siguiente cita podemos observar cómo se enfatiza una manera contra-hegemónica de narrar la conformación de la nación argentina que apela a una historia negra local y regional (rioplatense). Se destaca aquí también cómo la interpretación biológica de la "raza" (la "sangre negra") es re-encuadrada para leer un presente en función de una historia que explicaría las adopciones contemporáneas, en este caso, del candombe de origen afrouruguayo:

[...] nuestra nación se construyó con muchisimas personas negras que contribuyeron muchisimo a nuestra cultura, en la música, a la política, a muchos elementos de nuestra cultura, no era la Argentina sino la cultura del Río de la Plata y eso está presente en el inconsciente colectivo. $Y$ entonces creo que este fenómeno candombero tiene que ver con que hay una memoria colectiva que de algún modo se despierta y está atenta a estas agrupaciones que si nos remitimos a la historia, no eran sólo "nos juntamos a tocar", eran sociedades de ayuda mutua, era la gente del pueblo organizado y organizando distintos eventos para poder en su momento comprar la libertad, después fueron surgiendo otras cuestiones, y eso está. [...] o sea, en nuestra sangre, genéticamente nuestra información está eso latente y muy presente, somos eso, somos parte de esa historia que sabe desde el inconsciente colectivo que el tomar la calle, el unirnos, el organizarnos más allá de lo musical o desde lo musical y de lo artístico, puede llevar a cosas mucho más complejas e interesantes conjuntas [...] (Bailarina de candombe, registro de observación participante en Encuentro de LTNC $^{13}$ 29/10/2011, ciudad de Buenos Aires).

Sin embargo, aunque estas preguntas sobre la negritud pueden llevar a la búsqueda o reconocimiento de ancestros afro, indigenas y/o mestizos, la práctica de un arte negra (muchas veces en interrelación con la de otras culturas populares) se vincula principalmente con acciones, discursos y resignificaciones en torno a formas de sensibilidad y goce estético, maneras de vivenciar el cuerpo (corporalidades), sociabilidad, esparcimiento, acción cultural - y en muchos casos también política. En congruencia con esto, muchas de las reflexiones que se verbalizan tanto en contextos de reflexión pública, como también en situaciones de entrevista, se esfuerzan en deslindar de qué maneras es vivida y resignificada una expresión cultural afro más allá - aunque no necesariamente desvinculadas - de identificaciones y causas afrodescendientes. En varias de estas ocasiones, entran en juego las vinculaciones entre representaciones sobre las culturas negras y procesos ideológicos relacionados con experiencias de socialización generacional a partir de las cuales una práctica cultural afro puede ser reelaborada y reinterpretada para enmarcar y dar contenido a búsquedas identitarias tanto personales como sociales (Lamborghini 2015. 2017a, 2017b). Formas horizontales de organización, deconstrucciones del sistema de género, sentidos de comunidad y de cultura independiente. experiencias y significaciones alternativas del cuerpo, performatividad cultural en el espacio público y su lugar en la expresión de protestas y luchas políticas, son todos procesos profundizados a partir de la crisis neoliberal de 2001 (Lamborghini 2015). Así, la práctica vigorosa (es decir; no el mero "consumo") de artes afrolatinoamericanas puede

13 Encuentro del colectivo de candombe Los Tambores No Callan (LTNC). 
facilitar, entre otros procesos, su re-politización y dar lugar a distintas capas de sentido de performance y memoria, como en la movilización anual masiva por los derechos humanos de la última dictadura militar (y del presente), donde performances afro reúnen y vinculan pasado, presente y futuro conjugando distintas temporalidades y tradiciones de resistencia. ${ }^{14}$

Debido a las particularidades del contexto local - con la negación histórica de la negritud actuando como telón de fondo - y dada la riqueza y las particularidades del campo de actividades artísticas y políticas afro, podemos plantear que, aunque en este caso la cultura afro no se entrelace con una identidad personal o colectiva afrodescendiente, la práctica y re-semantización de performances afro también contribuye al cuestionamiento de la narrativa dominante de la nación argentina blanca- europea y de la regulación racializada del espacio público cuando se sostiene su práctica en esta esfera (Lamborghini 2015). Así, las acciones de resistencia y presencia en el espacio público suelen ser insertadas dentro de una prolongada serie de contiendas cuyo origen puede establecerse en la época de la esclavitud:

Me parece que el candombe es resistencia y es reivindicación de las raices afro, porque en la época colonial un negro por tocar tambor podia ser azotado. Con doscientos azotes [...] hablar del tambor y la danza en el espacio público es reivindicar las raices afro y nuestro momento actual, esto de ser libres, de poder ocupar este lugar y poder danzar y poder tocar (Otra bailarina de candombe, registro de observación participante en Encuentro de LTNC, 29/10/2011, ciudad de Buenos Aires).

Este campo de análisis nos permite también una entrada a la problematización de resignificaciones y relocalizaciones de prácticas culturales ${ }^{15}$ afro por fuera de sentidos de canibalización y banalización (Lamborghini 2017b) y complejizar la misma noción de "blanquitud" que, como la de su contraparte, la "negritud", constituyen categorias polisémicas, escurridizas y contradictorias (Lamborghini y Geler 2016).

Este tipo de resignificaciones nos llevan asimismo a observar intersecciones entre organizaciones afro y grupos artísticos que practican alguna forma de cultura afro con mayor o menor grado de tensión según los momentos, ámbitos y en relación a procesos y posicionamientos construidos a lo largo del tiempo. En un contexto en el que las narrativas multiculturalistas dan lugar a la revisibilización de identidades minorizadas y negadas, pero también a esencialismos culturales (no exentos de trampas), se encuentran los procesos, también crecientes, de mercantilización y "fetichización" de géneros tradicionales, como sucede particularmente con los afroamericanos bajo modelos neoliberales de la cultura (Carvalho 2002). Este trasfondo de tendencias marcadas nos permite adoptar una perspectiva compleja respecto de las situaciones de intercambio, diálogo y des/articulaciones.

\section{Des/articulaciones entre procesos} identitarios y adscripciones culturales afro: algunas líneas de comparación posibles

En los apartados anteriores desarrollamos, en primer lugar, cómo se articula la dimensión étnico-racial "afro" en trayectorias personales inscriptas en colectivos que se identifican afrodescendientes en un contexto mayor de visibilización y reivindicación étnico-política. En el caso de los y las jóvenes argentinos/as de ascendencia caboverdiana, es interesante notar cómo una identidad afrodescendiente puede modelarse y/o reforzarse mediante narrativas y preguntas desencadenadas al comprometerse y practicar algunas formas de expresión cultural afro/negra. Como vimos, estas prácticas entregan elementos ligados a la propia representación de las culturas negras que se confrontan con las formas en que ha sido tramitada la historia de lo

14 Eva Lamborghini. Performances afro y movilización social: articulaciones entre arte, politica y memoria en Buenos Aires. En prensa. Revista Cuicuilco.

15 Partimos de una noción general de "cultura" que enfatiza su dimensionalidad - y no su sustancialidad (Appadurai 2001) - para abordarla "menos como una propiedad de los individuos y grupos y más como un recurso heurístico que podemos usar al hablar de las diferencias" (Appadurai 2001, 28). 
negro (y el consecuente racismo) entre las familias argentino-caboverdianas. Esto habilita a algunos/ as jóvenes a expresar de nuevas maneras sus vivencias, ya sea manifestando diversos reclamos ligados al racismo, incluyendo otras memorias soslayadas, pero también integrándose en ámbitos no necesariamente negros (talleres brindados por profesores no afrodescendientes y/o con pares no afro) que les otorgan un margen más amplio de expresividad, a diferencia de los marcos anclados desde recortes socio-étnicos, raciales y familiares que, derivados de una experiencia cotidiana de marcación, visualizaban lo racial como un marcador de pertenencia étnica. Estas prácticas les permiten entonces participar de una identidad afro más genérica, africanizándose, y acercándose a prácticas culturales respecto de las cuales las familias tomaban distancia. Al mismo tiempo, les permite salirse del mote de "negros" por asociación familiar y participar de otros espacios. De la mano de prácticas artísticas, sobre las que estos/as jóvenes se orientan en un contexto de expansión de estas artes en Buenos Aires, recrean una idea diferente de pertenencia, que si bien por momentos se apoya en los vinculos familiares, reavivando recuerdos e iniciando búsquedas, van más allá de estos creando y transformando sus sentidos entre quienes los practican.

En segundo lugar, nos referimos a un proceso que, asi como también se desarrolla bajo el marco del multiculturalismo, ha sido coadyuvado asimismo por la reactivación de saberes y prácticas populares en general desde el retorno democrático. A partir de estos procesos, y de otros profundizados a partir de la crisis de 2001, como el vuelco de la cultura al espacio público y mayores articulaciones entre expresividad cultural y política (Lamborghini 2017a, 2017b), las "culturas negras" (Frigerio 2000; Hall 2003); Sansone 2003) fueron cobrando cada vez mayor relieve en segmentos argentinos mayormente juveniles y de sectores medios cuyo acercamiento a estas artes se produce de diversas maneras y a partir de distintas búsquedas: recreación personal; sociabilidad; de expresión musical; corporal; artística; expresión y movilización política, etc. Las resignificaciones en manos de estos/as practicantes implican en muchos casos "llevar" a las expresiones culturales afro incorporadas marcos de interpretación y acción vinculados a su socialización generacional más amplia y, al mismo tiempo, estas prácticas y sus reelaboraciones en ocasiones se ven permeadas por representaciones de las culturas negras como parte de una historia argentina negada y silenciada. Vimos cómo estas relocalizaciones nos permiten entonces problematizar resignificaciones de artes afro en sectores que adscriben culturalmente a las mismas desde sentidos que, aunque no gravitan en torno a la afrodescendencia o negritud, ya sea personal y/o como parte de un colectivo que reivindica estos orígenes, también confluyen en el cuestionamiento de la "Argentina blanca" y cuya visibilidad performática y presencia pública se arraiga de manera contundente.

Asi como lo afro en tanto "cultura afro" viene visibilizándose y siendo incorporado entre sectores de la sociedad argentina más amplia. los y las jóvenes argentino-caboverdianos/as afrodescendientes también fueron apropiándose de culturas afro y estas apropiaciones, entre otras cosas, les posibilitaron desafiar algunas formas del racismo, que los reubicaba en espacios familiares fijos y permanentes. Podemos decir entonces que, mientras que las adscripciones culturales en segmentos mayormente juveniles y medios argentinos "no afro" problematizan sus propias inserciones en la construcción de la blanquitud nacional, en ocasiones oponiéndose a sentidos y prácticas hegemónicas a partir de resignificaciones de "resistencias negras", la práctica de culturas afro por jóvenes argentino-caboverdianos/as que se reconocen afrodescendientes les permite recrear identidades alternativas que, si bien abrevan en la africanización, van más allá de los sentidos raciales a los que usualmente quedan ligados por pertenencia familiar.

\section{Palabras finales}

En este trabajo nos propusimos comenzar un análisis dialógico que tenga en cuenta 
convergencias, divergencias y particularidades entre lo que simplificadamente puede definirse como "ser (o no) afrodescendiente" y "practicar cultura afro" en Buenos Aires. En una ciudad (y un país) donde las memorias afrodescendientes emergen en la voz y lucha de actores políticos afrodescendientes sobreponiéndose a históricos borramientos, y donde la práctica cotidiana y pública de manifestaciones culturales afro es cada vez más notoria, las artes negras ofrecen elementos ligados a las representaciones de las culturas negras que entran en juego con inserciones familiares y trayectorias inscriptas, o no, en identificaciones afrodescendientes, pero que comparten lecturas críticas sobre las formas en que ha sido narrada la historia y el lugar de los africanos y africanas esclavizados/ as y sus descendientes en el pasado y presente argentino y, de esta manera, adscriben a una historia afroargentina/afrodescendiente a partir de la cual repensar trayectorias propias y formas diferentes de pertenencia.

Numerosas líneas de indagación pueden plantearse y seguir profundizándose, en este artículo avanzamos en aunar y articular en un mismo trabajo esferas de análisis que suelen mantenerse separadas, tanto en los estudios académicos como en los campos discursivos y de acción que estos abordan, pero entre los que se producen, sin embargo, interesantes puntos de intersección, préstamos y tránsitos cuya puesta en diálogo puede contribuir a la complejización y no esencialización de las identidades y las culturas que "les corresponden" (Juárez Huet y Rinaudo 2017), abordando procesos que no son necesariamente lineales. De esta manera, indagar en las formas en que las prácticas culturales afrolatinoamericanas son reelaboradas de acuerdo a distintas representaciones de culturas negras que las enmarcan y dan sentido, posibilitando nuevas corporalidades, formas de pertenencia, expresividad cultural y política en distintos sectores sociales y en relación a clivajes de (auto)adscripción disímiles, permite iluminar convergencias y divergencias en campos de confluencia - con mayores o menores tensiones - antes que de separación, y según dinámicas contextuales nacionales particulares. Esto, consideramos, podría ser de utilidad no sólo analítica sino también en la proyección de acciones políticas - en el caso argentino - de mayor alcance y en consonancia con las propias realidades.

\section{Referencias}

Appadurai, Arjun. 2001. La modernidad desbordada. Dimensiones culturales de la globalización. Buenos Aires: FCE, Ediciones Trilce.

Briones, Claudia. 2002. Mestizaje y blanqueamiento como coordenadas de aboriginalidad y nación en Argentina, Runa 23: 61-88.

Carvalho, José Jorge de. 2002. Las tradiciones musicales afroamericanas: de bienes comunitarios a fetiches transnacionales. Serie Antropología UnB 320: 2-25.

Corti, Berenice. 2015. Jazz argentino. La música "negra" del pais "blanco". Buenos Aires: Gourmet Musical.

Dominguez, Maria Eugenia. 2004. O 'Afro' entre os imigrantes em Buenos Aires: Reflexões sobre as diferenças. Tesis de Mestrado em Antropologia Social, Universidade Federal de Santa Catarina, Centro de Filosofia e Ciências Humanas, Programa de Pós- graduação em Antropologia Social. https://doi.org/10.5380/cam.v5i2.1631

Fernández Bravo, Nicolás. 2012. ¿Qué ha cambiado en el 'campo afro'? Paradojas, temporalidades, desafíos. In Afropolíticas en América del Sur y el Caribe, organizado por Milena Annechiaricco y Alicia Martin, 73-88. Buenos Aires: Puentes del Sur. https://doi. org/10.35537/10915/4591

Frigerio, Alejandro. 2000. Cultura negra en el Cono Sur: representaciones en conflicto. Buenos Aires: Ediciones de la Universidad Católica Argentina.

Frigerio, Alejandro. 2006. "Negros" y "blancos" en Buenos Aires: repensando nuestras categorias raciales. Temas de Patrimonio Cultural 16: 77-98.

Frigerio, Alejandro, e Eva Lamborghini. 2011a. Los afroargentinos: formas de comunalización, creación de identidades colectivas y resistencia cultural y politica. In Afrodescendientes y africanos en Argentina, organizado por Rubén Mercado e Gabriela Catterberg, 1-51. Buenos Aires: Programa de las Naciones Unidas para el Desarrollo (Pnud). https://doi.org/10.21678/apuntes.39.450

Frigerio, Alejandro, e Eva Lamborghini. 2011b. Procesos de reafricanización en la sociedad argentina: umbanda, candombe y militancia "afro". Pós Ciencias Sociais 16: 21-35

Geler, Lea. 2010. Andares negros, caminos blancos. Afroporteños, estado y nación. Argentina a fines del siglo XIX. Rosario: Prohistoria; Barcelona: TEIAA. 
Geler, Lea. 2011. ¿Quién no ha sido negro en su vida? Performances de negritud en el carnaval porteño de fin de siglo (XIX-XX). In El Estado en América Latina. Recursos e imaginarios, siglos XIX-XXI, organizado por Pilar García Jordán, 183-211. Universidad de Barcelona. https://doi.org/10.4000/books.ifea.7228

Geler, Lea. 2016. Categorias raciales en Buenos Aires. Negritud, blanquitud, afrodescendencia y mestizaje en la blanca ciudad capital. Revista Runa. Archivo para las ciencias del hombre 37: 71-87. https://doi.org/10.34096/ runa.v39i2.4185

Hall, Stuart. 2003. Da diáspora: identidades e mediações culturais. Organizado por Liv Sovik, Belo Horizonte: Editora UFMG; Brasilia: Representação da Unesco no Brasil.

Hall, Stuart. 2010. Sin garantias: trayectorias y problemáticas en estudios culturales. Organizado por Eduardo Restrepo, Catherine Walsh, e Victor Vich. Instituto de estudios sociales y culturales Pensar, Universidad Javeriana; Instituto de Estudios Peruanos; Universidad Andina Simón Bolivar sede Ecuador: Envión Editores. https://doi.org/10.22191/gobernar/vol2/iss3/5

Juárez Huet, Nahayeilli, e Christian Rinaudo. 2017. Expresiones "afro": circulaciones y relocalizaciones. Desacatos 53: 8-19. https://halshs.archives-ouvertes. fr/halshs-01447654

Lamborghini, Eva. 2015. Candombe afro-uruguayo en Buenos Aires: Nuevas formas de sociabilidad, politica y apropiación del espacio público. Tesis de doctorado, Universidad de Buenos Aires. https://doi.org/10.21840/siic/153099

Lamborghini, Eva. 2017a. Apropiaciones y resignificaciones de las "culturas negras": la práctica del candombe afro-uruguayo en sectores juveniles blancos de Buenos Aires (Argentina). Universitas Humanistica 83: 291-318. https://doi.org/10.11144/javeriana.uh83.arcn

Lamborghini, Eva. 2017b. Los tambores no callan: candombe y nuevos ethos militantes en el espacio público de Buenos Aires. Revista Runa. Archivo para las ciencias del hombre, 38 (1): 111-129. https://doi.org/10.34096/ runa.v39i1.3883

Lamborghini, Eva y Lea Geler. Presentación del debate: Imágenes racializadas: políticas de representación y economía visual en torno a lo "negro" en Argentina. siglos XX y XXI, Corpus. Archivos virtuales de la alteridad americana 6, n. 2: 1-14. http://journals.openedition. org/corpusarchivos/1735. https://doi.org/10.4000/ corpusarchivos.1735

Lamborghini, Eva, Lea Geler, e Florencia Guzmán. 2017. Los estudios afrodescendientes en Argentina: nuevas perspectivas y desafios en un país "sin razas". Tabula Rasa 27: 68-101. https://doi.org/10.25058/20112742.445

Lao Montes, Agustín. 2009. Cartografías del campo político afrodescendiente en América Latina. Universitas Humanistica 68: 207-245.

Maffia, Marta. 2010. Desde Cabo Verde a la Argentina. Migración, parentesco y familia. Buenos Aires: Biblos.
Maffia, Marta. 2011. La migración subsahariana hacia Argentina: desde los caboverdianos hasta los nuevos migrantes del siglo XXI. In Aportes para el desarrollo humano en Argentina/2011: afrodescendientes y africanos en Argentina, organizado por Rubén Mercado, e Gabriela Catterberg, 53-89. Buenos Aires: Pnud. https:// doi.org/10.17227/01234870.41folios87.102

Margulis, Mario, e Marcelo Urresti. 2008. La juventud es más que una palabra. In La juventud es más que una palabra. Ensayos sobre cultura y juventud, organizado por M. Margulis, 13-28. Buenos Aires: Biblos. https:// doi.org/10.14409/ie.v1i3.3919

Martino, María Cecilia. 2015. Afro/argentinos caboverdianos de Buenos Aires. Procesos históricos, políticos e identitarios desde una perspectiva intergeneracional. Tesis de doctorado, Universidad de Buenos Aires. https://doi.org/10.20319/pijss.2017.32.20152033

Martino, Maria Cecilia. 2016. Reflexiones sobre imágenes fotográficas, vínculos familiares e identidades entre argentinos/caboverdeanos de Buenos Aires, Corpus. Archivos virtuales de la alteridad americana 6 n. 2: 1-10. http://journals.openedition.org/corpusarchivos/1746 https://doi.org/10.4000/corpusarchivos.1746

Martino, María Cecilia. 2017. Memorias y redefinición de identidades en torno al proceso de independencia en Cabo Verde. El caso de los argentino-caboverdianos en Buenos Aires. Runa, Archivos para las Ciencias del Hombre 2: 21-35. https://doi.org/10.340g6/runa.v3gi2.4185

Otero Correa, Natalia. 2000. Afroargentinos y caboverdeanos: las luchas contra la invisibilidad de la negritud en Argentina. Tesis de Maestría, Facultad de Humanidades y Ciencias Sociales, Universidad Nacional de Misiones. https://doi.org/10.19137/cienvet2015-1715

Sansone, Livio. 2003. Blackness without ethnicity: constructing race in Brasil. New York: Palgrave MacMillan. https://doi.org/10.1353/tam.2005.0057

\section{Eva Lamborghini}

Doutora em Antropologia. Bolsista de pós-doutorado do Consejo Nacional de Investigaciones Científicas y Tecnológicas (Conicet) no Instituto de Historia Argentina y Americana Dr. Emilio Ravignani. Universidad de Buenos Aires (UBA), en Buenos Aires, Argentina. Docente da Faculdade Latino-Americana de Ciências Sociais (Flacso), Buenos Aires, Argentina.

\section{María Cecilia Martino}

Doutora em Antropologia. Bolsista de pós-doutorado do Consejo Nacional de Investigaciones Científicas y Tecnológicas (Conicet) no Instituto de Ciencias Antropológicas FFyL. Docente da Universidad de Buenos Aires (UBA), Buenos Aires, Argentina. 